\title{
Laccase-Modified Gold Nanorods for Electrocatalytic Reduction of Oxygen
}

\author{
Chiara Di Bari ${ }^{\dagger}$ Sergey Shleev, ${ }^{*}$ Antonio L. De Lacey, ${ }^{*}{ }^{\dagger}$ and Marcos Pita ${ }^{*}, \dagger$ \\ †Instituto de Catálisis y Petroleoquimica, CSIC, c/Marie Curie 2, L10, 28049 Madrid, Spain. \\ ${ }^{\ddagger}$ Biomedical Sciences Faculty of Health and Society, Malmo University, SE-205 06 Malmo, \\ Sweden. \\ e-mail: alopez@icp.csic.es marcospita@icp.csic.es
}


Keywords: Laccase; Graphite; Gold nanorod; Biocathode; Biofuel cell.

\begin{abstract}
The multicopper oxidase Trametes hirsuta laccase (ThLc) served as a bioelectrocatalyst on nanostructured cathodes. Nanostructuring was provided by gold nanorods (AuNRs), which were characterized and covalently attached to electrodes made of low-density graphite. The nanostructured electrode was the scaffold for covalent and oriented attachment of ThLc. The bioelectrocatalytic currents measured for oxygen reduction were as high as $0.5 \mathrm{~mA} / \mathrm{cm}^{2}$ and $0.7 \mathrm{~mA} / \mathrm{cm}^{2}$, which were recorded under direct and mediated electron transfer regimes, respectively. The experimental data were fitted to mathematical models showing that when the $\mathrm{O}_{2}$ is bioelectroreduced at high rotation speed of the electrode the heterogeneous electron transfer step is the rate-liming stage. The electrochemical measurement hints a wider population of non-optimally wired laccases than previously reported for 5-8 nm size Au nanoparticles-modified electrode, which could be due to a larger size of the AuNRs when compared to the laccases as well as their different crystal facets.
\end{abstract}




\section{Introduction}

Laccases, formally known as polyphenol oxidases, are enzymes from the oxidorreductases group known as blue multicopper oxidases, which also comprises bilirubin oxidase, ceruloplasmin and ascorbate oxidase. Laccases have an active site characterized by two different redox centers that contain $\mathrm{Cu}$ (II) ions separated in their folded structure. The first of these two centers contains a single $\mathrm{Cu}$ cation, named $\mathrm{T} 1$ site, and its function is to oxidize a substrate while stripping out four electrons in consecutive steps. The electrons go to the second center, the T2/T3 cupper trinuclear cluster, where $\mathrm{O}_{2}$ is reduced to $\mathrm{H}_{2} \mathrm{O}$ [1]. The $\mathrm{T} 1$ site redox potential ranges between $400-800 \mathrm{mV} v s$. NHE depending on the laccase natural source [1]. On the other side it is impossible to assess a single redox potential value for the T2/T3 cluster. The catalytic cycle of blue multicopper oxidases contemplates several cluster intermediates [2] that show different redox potentials from each other [3]. Although the values for such redox potentials are experimentally unknown, it is estimated is that they are relatively high [4] as some multicopper oxidases' intermediates show a strongly oxidizing and highly reactive behavior [5].

The redox potential of most fungal laccases is high, which allows a very interesting advantage: their ability to biocatalyze the reduction of $\mathrm{O}_{2}$ to $\mathrm{H}_{2} \mathrm{O}$ at very low overpotentials with $100 \%$ efficiency and at high turnover rates [1,6]. This characteristic allows such laccases to perform as bioelectrocatalysts in the cathodes of biofuel cells $[7,8]$. Biofuel cells can be utilized for implantable devices [9] and could take a part in future biomedical applications [10]. Including laccase as catalyst in a biocathode requires its immobilization on the electrode and the substitution of its natural electron donor substrate by the electrode itself. Redox mediators can facilitate this step, yielding very high biocatalytic $\mathrm{O}_{2}$ reduction only limited by the $\mathrm{O}_{2}$ difussion rate to the enzymatic electrode $[11,12]$. However, mediated electron transfer (MET) systems involve an additional redox process, therefore diminishing the catalytic redox 
potential from that of the laccase to the mediator's one. Another possibility is to avoid mediators aiming to maximize the onset potential for $\mathrm{O}_{2}$ reduction; such approach means developing laccase biocathodes based on direct electron transfer (DET). In this case the goal is obtaining biocatalytic currents as intense as those of MET-based electrodes while minimizing the $\mathrm{O}_{2}$ reduction overpotential and putting apart the typical problems brought by redox mediators. Achieving such goal requires that the reduction of $\mathrm{O}_{2}$ performed by the laccase biocathode takes place at the T1 site of the laccase and not at the T2/T3 $\mathrm{Cu}$ site [6].

Several strategies to connect laccase and the electrodes by DET have been published either relying on the oriented immobilization of the laccase [13-16] or on its coimmobilization with conductive nanostructures [17-21]. Particularly successful works wired the laccase to graphite electrodes by means of carbon nanotubes, in which the catalytic current was mass-transport limited [22], or by gold nanoparticles that could act as electronic bridges [23]. The latter work showed that small-enough gold nanoparticles (AuNPs) could connect the enzyme active site and the electrode very efficiently; consequently the electron transfer between the laccase and the electrode ceased to limit the whole process and a Nernstian-like process was achieved [23]. Such result opened new interest on wiring laccase to electrodes enhanced by nanoelements.

In the present work we study an alternative disposition of the nanostructured gold, namely nano-rods (AuNRs). The Rod-shape offers different crystalline facets that translate into different physico-chemical properties. This new configuration may give some hints to improve the direct electron transfer of the laccase. It is well known that crystalline surface of gold affects its electrical properties [24]. Low-density graphite (LDG) has been used as suitable electroactive material for DET of laccases due to its high surface area, pores distribution and low price $[23,25,26]$. Indeed, the combination of AuNRs and LDG as shown 
in Scheme 1 is used as platform for studying the electrocatalytic reduction of oxygen by immobilized laccase.

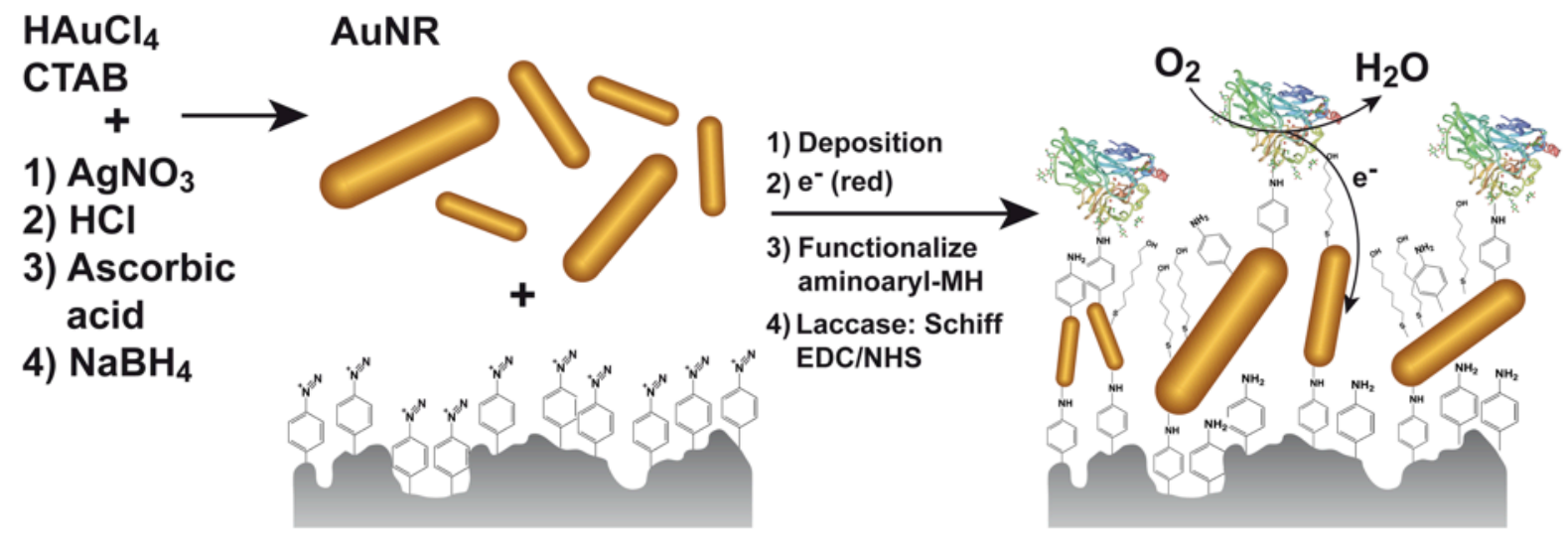

Scheme 1. Preparation of AuNR-LDG electrodes and laccase immobilization.

\section{Materials and Methods}

Chemicals. All reagents were purchased with ACS purity grade. $\mathrm{HAuCl}_{4}$, Tetrakis(hydroxymethylphosphonium chloride) (THPC), Hexadecyltrimethylammonium bromide (CTAB), silver nitrate, L-ascorbic acid, sodium tetrahydridoborate, 4-nitrobenzene diazonium perchlorate, $\mathrm{BF}_{4} \mathrm{Bu}_{4} \mathrm{~N}$, sodium nitrite, 6-mercapto-1-hexanol (MH), 1-(3dimethylamino-propyl)-3-ethylcarbodiimide (EDC), morpholino-ethanesulphonic acid (MES), 2,2'-azinobis-(3-ethylbenzothiazoline-6-sulfonic acid) diammonium salt (ABTS), $\mathrm{NaClO}_{4}, \mathrm{AgNO}_{3}$ and $\mathrm{NaF}$ were purchased from Sigma. $98 \% \mathrm{H}_{2} \mathrm{SO}_{4}$, absolute ethanol (EtOH), hydrochloride acid $37 \%$, acetic acid $96 \%, \mathrm{NaIO}_{4}$, sodium hydroxide, sodium chloride, disodium hydrogen phosphate and acetonitrile HPLC grade were purchased from Panreac. Nhydroxysuccinimide (NHS) was obtained from Fluka. Milli-Q grade (Millipore) water was used for preparing aqueous solutions.

Enzyme. Trametes hirsuta lacasse (ThLc), strain T. hirsuta 56, was purified at the Moscow State University of Engineering Ecology as reported [27]. SDS-PAGE and HPLC 
showed that the enzyme was homogeneous. The concentration of the enzyme was determined by the Bradford method [28] using BIO-RAD (Bio-Rad Laboratories) and bovine serum albumin (BSA)for the calibration.

Synthesis of Gold Nanorods. A seedless growth technique was used for the synthesis of gold nanorods with low dimensions and aspect ratio [29]. The growth solution was prepared at $30{ }^{\circ} \mathrm{C}$ by the addition of $5 \mathrm{~mL} \mathrm{HAuCl}_{4} 1 \mathrm{mM}$ and $5 \mathrm{~mL}$ CTAB $0.2 \mathrm{M}$, followed by the introduction in the following order of: $250 \mu \mathrm{L} \mathrm{AgNO}_{3} 4 \mathrm{mM}, 8 \mu \mathrm{L} 37 \% \mathrm{HCl}, 70 \mu \mathrm{L}$ ascorbic acid $78.8 \mathrm{mM}$ and $15 \mu \mathrm{L}$ ice-cold $0.01 \mathrm{M} \mathrm{NaBH}_{4}$. Nanorods formed almost immediately, which is detected by a color change to deep red and by TEM imaging. However, in order to obtain a uniform morphology and an adequate yield, the samples were left to grow overnight. Afterwards, the solution was centrifuged (6500 rpm for $30 \mathrm{~min})$. The supernatant was removed and the AuNRs were redispersed in deionized water and centrifuged at the same speed and time. The procedure was repeated for three times.

Synthesis of Gold Nanoparticles. AuNPs showing a diameter of $5 \pm 3 \mathrm{~nm}$ were synthesized prior to their use in aqueous media by addition of $1 \mathrm{mM} \mathrm{HAuCl} l_{4}$ to a solution containing $\mathrm{NaOH} 60 \mathrm{mM}$ and THPC $1 \mathrm{mM}$ while stirring vigorously [30]. The obtained nanogold dispersion was filtered with a PTFE $0.45 \mu \mathrm{m}$ pore size filter (Pall, Geldan Laboratory).

Preparation of AuNR-LDG Electrodes. Low density graphite (LDG, Sigma) electrodes were cleaned, polished and modified with 4-aminophenyl groups as reported previously [23]. Then, the modified electrodes were immersed in a $\mathrm{HCl} 0.5 \mathrm{M}$ solution containing $14.5 \mathrm{mM} \mathrm{NaNO}$ during $2 \mathrm{~h}$ in order to diazotate the anilinium groups on the electrode surface and facilitate the covalent bonding of the AuNRs. Afterwards the electrodes were covered overnight with $5 \mu \mathrm{L}$ of AuNRs suspension freshly centrifuged, washed and let to dry. Finally the AuNR-LDG electrodes were taken to an electrochemical cell and two 
cyclic voltammogramms were recorded at room temperature between 0.6 and $-0.6 \mathrm{~V}$ at 200 $\mathrm{mV} / \mathrm{s}$ using $50 \mathrm{mM}$ acetate buffer, $\mathrm{pH} 4.2, \mathrm{NaClO}_{4} 100 \mathrm{mM}$ as electrolyte.

Immobilization of $\boldsymbol{T}$. hirsuta Laccase. The AuNR-LDG electrodes were modified with the enzyme as reported before [23].

Electrochemical Measurements. An Autolab PGSTAT30 analyzer controlled by GPES 4.9 software (Eco Chemie) was used for electrochemical characterization. The threeelectrode glass cell comprised a BAS Ag/AgCl reference electrode (204 mV vs. NHE), a platinum wire as counter electrode and a LDG electrode connected to a MSR electrode rotator from Pine Instruments. The cell temperature during experiments was controlled at $30^{\circ} \mathrm{C}$ by a jacket with water recirculation. In the electrocatalytic measurements the current densities are reported relative to the geometric area of the electrodes $\left(0.28 \mathrm{~cm}^{2}\right)$ and the potential values are represented vs. $\mathrm{Ag} / \mathrm{AgCl}(3 \mathrm{M})$ as reference electrode. The bioelectrocatalytic cyclic voltammograms were recorded from 0.8 to $0 \mathrm{~V}$ at $10 \mathrm{mV} \cdot \mathrm{s}^{-1}$ using an electrolyte solution composed of $50 \mathrm{mM}$ acetate buffer $\mathrm{pH} 4.2,100 \mathrm{mM}$ of $\mathrm{NaClO}_{4}$ after bubbling $\mathrm{O}_{2}$ during 15 min. For MET measurements $0.1 \mathrm{mM}$ of ABTS was added. The equation used to fit the experimental resultswas Leger's theoretical equation (equation 6 of [31]) adapted to laccase electrocatalysis:

$$
i=\frac{i_{\lim }}{1+e^{f\left(E-E_{T 1}\right)}}\left(1+\frac{1}{\beta d_{0}} \ln \frac{1+e^{f\left(E-E_{T 1}\right)}+\frac{k_{c a t}}{k_{0}^{\max }} e^{\frac{f}{2}\left(E-E_{T 1}\right)}}{1+e^{f\left(E-E_{T 1}\right)}+\frac{k_{c a t}}{k_{0}^{\max }} e^{\frac{f}{2}\left(E-E_{T 1}\right)} e^{\beta d_{0}}}\right)
$$

Where $i$ is the catalytic current, $i_{\text {lim }}$ is the limiting current controlled by laccase catalysis, $f=F / R T$ where $T, F$ and $R$ are the temperature, Faraday and molar gas constants respectively, $E$ is the redox potential, $E_{T 1}$ is the redox potential of the T1 site of the laccase, $\beta d_{0}$ is a unit-less parameter accounting for the orientations dispersion of enzyme molecules taking part in the DET process [31], $k_{0}^{\max }$ is the rate constant for DET to the T1 site at the 
optimal laccase orientation and $k_{\text {cat }}$ is the overall apparent rate constant for laccase catalysis (including intramolecular electron transfer from the $\mathrm{T} 1$ to $\mathrm{T} 2 / \mathrm{T} 3$ sites, oxygen reduction to water at the T2/T3 site, and product and substrate transport within the laccase).

Transmission Electron Microscopy (TEM). The AuNR-LDG electrodes were abraded with sandpaper for $10 \mathrm{~s}$ for TEM analysis. The produced carbon chips were suspended in $500 \mu \mathrm{L}$ of $\mathrm{EtOH}$ and treated with ultrasounds for 30 min. A $20 \mu \mathrm{L}$ drop was taken from the particles' suspension and deposited on a Lacey Carbon Film 200 mesh copper TEM grid (Electron Microscopy Science) until it dried.

The AuNRs suspension for TEM analysis was centrifuged at $6500 \mathrm{rpm}$ for 30 minutes in order to remove the supernatant, then the nanorods were redispersed in water and centrifuged at the same speed and time for three times. A $20 \mu \mathrm{L}$ drop was taken from the solution, deposited on carbon film 200 mesh copper grid and let to dry.

The transmission electron microscope was a $200 \mathrm{KV}$ JEOL 2100 with an Oxford Instruments EDX analyzer. Gatan Micrograph software was used to acquire the images and measure the nanorods.

UV-Vis Spectroscopy. The AuNRs' absorption spectrum was measured using a Shimadzu UV-2401 PC spectrophotometer. $1 \mathrm{~mL}$ Disposable polycarbonate cuvettes were used.

\section{Results and Discussion}

The LDG electrodes were cleaned and modified for further covalent attachment of AuNRs. The modification procedure involved in the functionalization of the electrodes with a layer of 4-aminophenyl groups, which accomplished as described in earlier reports [23,25]. This modification is known to minimize the formation of multiple layers of aminoaryl 
derivatives on the electrode surface by using the above-specified parameters for the scan rate and the number of sweeps during the cyclic voltammetry experiments. The anilinium groups attached to the LDG surface were chemically turned into diazonium groups by introducing the modified electrode in a $14.5 \mathrm{mM} \mathrm{NaNO}, 0.5 \mathrm{M} \mathrm{HCl}$ solution. The diazonium-modified electrode was afterwards taken into an AuNRs aqueous dispersion during 18 hours, time that has been optimized for the present system and is different from the optimal time needed for AuNPs [23]. Finally a mixed monolayer construction of 4-aminophenyl and 6-mercapto-1hexanol was assembled on the AuNR-LDG. This specific construction allows the immobilization of ThLc keeping its T1 site oriented to the electrode surface $[15,16]$.
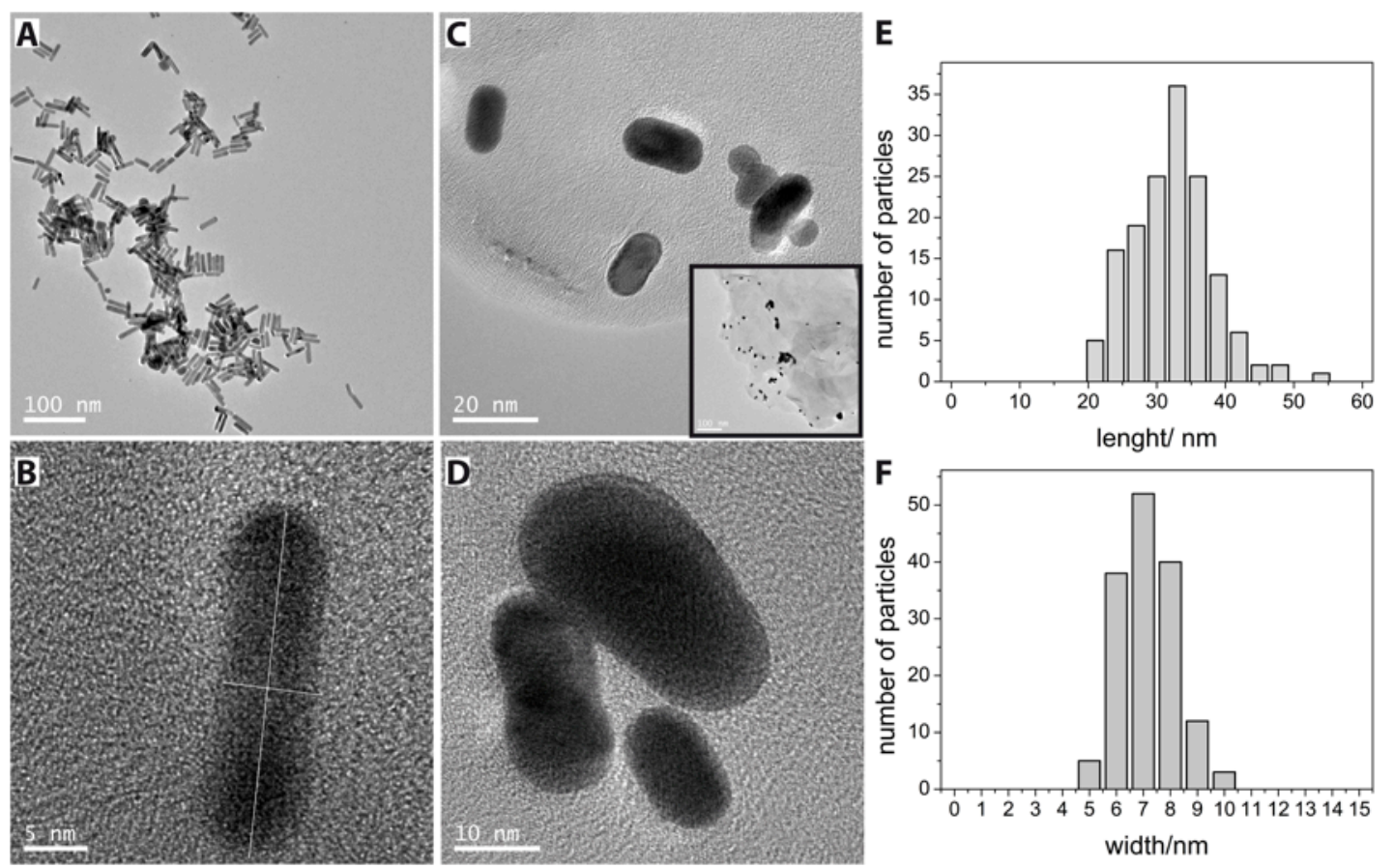

Figure 1. TEM images showing the AuNRs synthesized prior (A, B) and after their immobilization on the surface of functionalized LDG $(C, D)$. E and F show the measured length and width of the AuNRs in Figure 1A.

TEM samples of the AuNRs were measured before and after their immobilization (Figure 1). As it can be seen, most $\mathrm{Au}$ nucleated in rod shape (Figure 1A, B). The measurement of 150 rods showed an average size of $31 \pm 6 \mathrm{~nm}$ length and $5 \pm 1 \mathrm{~nm}$ width, meaning a length-to-width ratio of approximately 6 (Figure 1E, F). The AuNRs covalently 
attached to the electrode cannot be measured by TEM, therefore a modified AuNR-LDG electrode was scraped and the graphite powder produced was recovered and dispersed into solvent, which was used to prepare the TEM samples (Figure 1C, D). The inset of Figure 2C shows a large-scale TEM image of a graphite chip including a high load of gold nanorods. As the microscope is equipped with an EDX elemental analysis module, we could confirm that the dark rods correspond to elemental gold. However, a couple of facts should be noted: firstly the physical process used to produce the graphite chips by abrading the electrode may have diminished the total amount of gold retained on the electrode. Secondly, as it can be noticed in TEM images, the AuNRs show a deformed shape after their immobilization on the LDG and further run of electrochemical voltammograms, which is known to alter the shape of immobilized gold particles [32]. Nevertheless, the pictures show that a massive aggregation of rods on the LDG does not take place, which may be due to the covalent bonding between LDG and the Au-NRs that minimizes the mobility of Au on the electrode.

UV-Vis spectra of aqueous dispersions of the AuNRs were also measured Figure 2A, line a) and compared with the spectral response of gold nanoparticles (AuNPs) (figure 2A, line b). As can be observed, the typical spectrum of AuNPs shows the characteristic single localized surface Plasmon resonance absorption band centered at $\lambda=520 \mathrm{~nm}$. The AuNRs spectrum (line b) shows two localized surface Plasmon resonance bands, the same band at $\lambda=520 \mathrm{~nm}$ and another one at $\lambda=780 \mathrm{~nm}$. This response is typical for gold nanorods [33]. Moreover, as silver was used in the synthetic process, it was checked that there was no absorption band at $\lambda=410 \mathrm{~nm}$ in the spectrum $\mathrm{b}$, excluding any possibility to have obtained silver nanoparticles as by-product. 

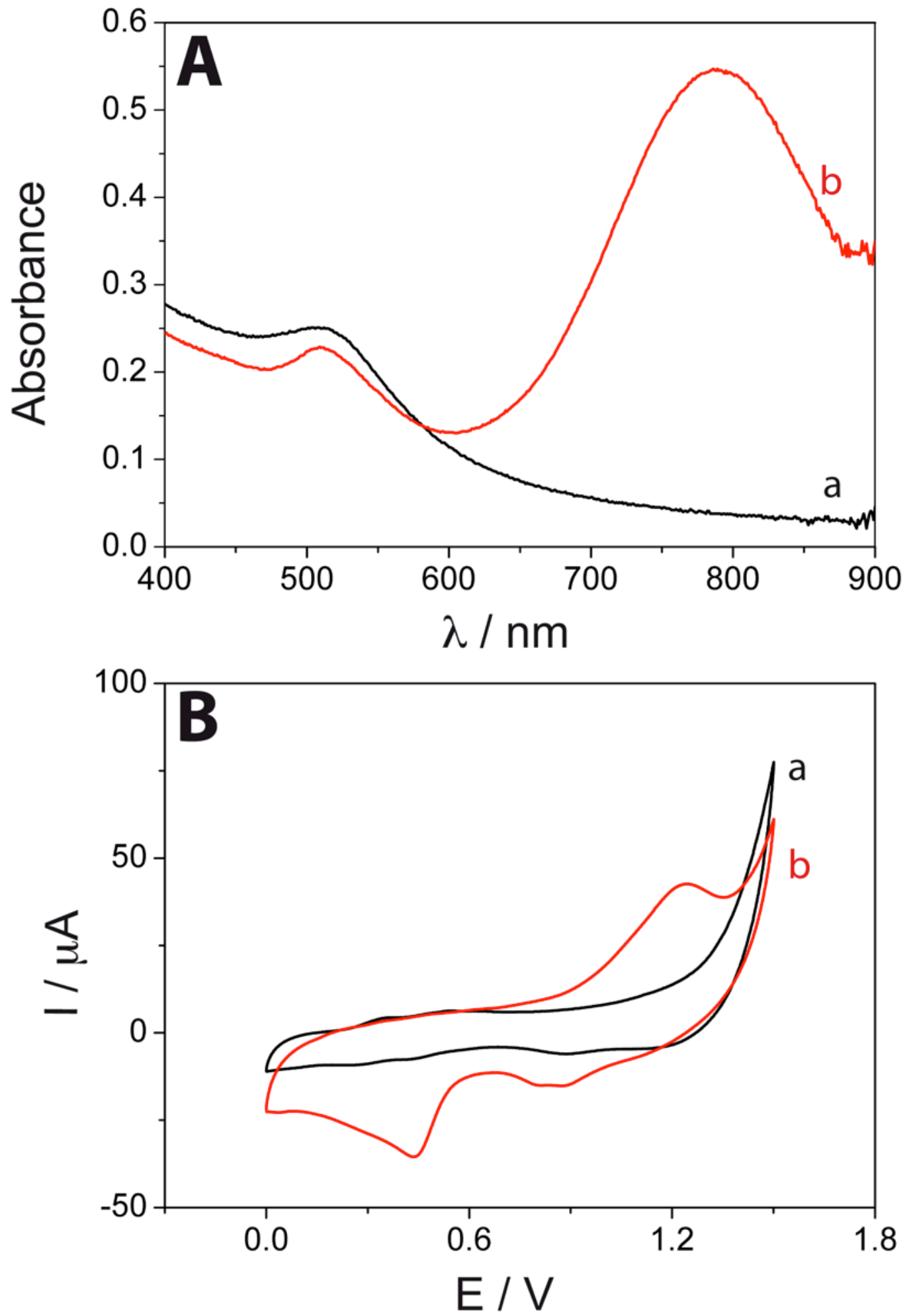

Figure 2. (A) UV-Vis spectra acquired for (a) Au nanoparticles and (b) Au nanorods. (B) Cyclic voltammograms acquired for (a) aminophenyl-functionalized LDG electrode and (b) AuNR-modified LDG electrode recorded in $\mathrm{H}_{2} \mathrm{SO}_{4} 0.1 \mathrm{M}$ electrolyte. 
The AuNR-LDG electrodes were also characterized electrochemically. It is possible to observe the typical amperometric redox processes of gold when it is immobilized as nanoparticles on the surface of graphite electrodes [23,34]. Figure $2 \mathrm{~B}$ reveals the cyclic voltammograms $(\mathrm{CVs})$ in $0.1 \mathrm{M} \mathrm{H}_{2} \mathrm{SO}_{4}$ of a LDG electrode before (curve a) and after (curve b) the covalent immobilization of AuNRs. The gold is responsible of a single anodic process that reaches its maximum at $+1.2 \mathrm{~V}$ vs. $\mathrm{Ag} / \mathrm{AgCl}$, and three cathodic reduction waves: two of them similar in magnitude centred at 0.8 and $0.75 \mathrm{~V}$ vs. $\mathrm{Ag} / \mathrm{AgCl}$ and a more intense one at $0.5 \mathrm{~V}$ vs. $\mathrm{Ag} / \mathrm{AgCl}$. It is known that the different facets of crystalline gold present different redox potentials [24], and the surface of the nanorods' tops is lower than that of the cylinder. Thus we can attribute the two highest potential reduction processes to the tops of the cylinder, whereas the body of the cylinder, which shows a lower redox potential but higher area, may correspond to the body center of the rod. The total surface of Au covalently bonded to the graphite surface was estimated by integrating the obtained gold oxide reduction peaks in Figure $2 \mathrm{~B}$, considering a charge equivalent of $-482 \mu \mathrm{C} \cdot \mathrm{cm}^{-2}$ needed to electrically reduce a gold oxide monolayer [24]. The CV shown in Figure 2B indicates that the electrodes of AuNR-LDG have a bound gold surface area of $0.7 \pm 0.2 \mathrm{~cm}^{2}$, which is 10 times the geometric area of the electrode. This value indicates that a high load of AuNRs have been covalently attached to the inner part of the LDG pores. The response of an AuNR-LDG was compared to the one of a typical AuNP-LDG electrode (Fig S1), in which the reduction peak at at $0.8 \mathrm{~V}$ predominates.

The AuNR-LDG electrodes were the scaffold for oriented and covalent immobilization of ThLc. In order to achieve such construction the surface was modified with a mixture of an incomplete monolayer of aminoaryl groups and 6-mercapto-1-hexanol (MH). It is known from previous work that the diazonium modification procedure can be controlled 
to form an incomplete monolayer of covalently bonded aromatic derivatives, allowing $\mathrm{MH}$ to form self-assembled monolayers on either the bare gold regions or those covered by physically adsorbed molecules $[15,16,35]$.
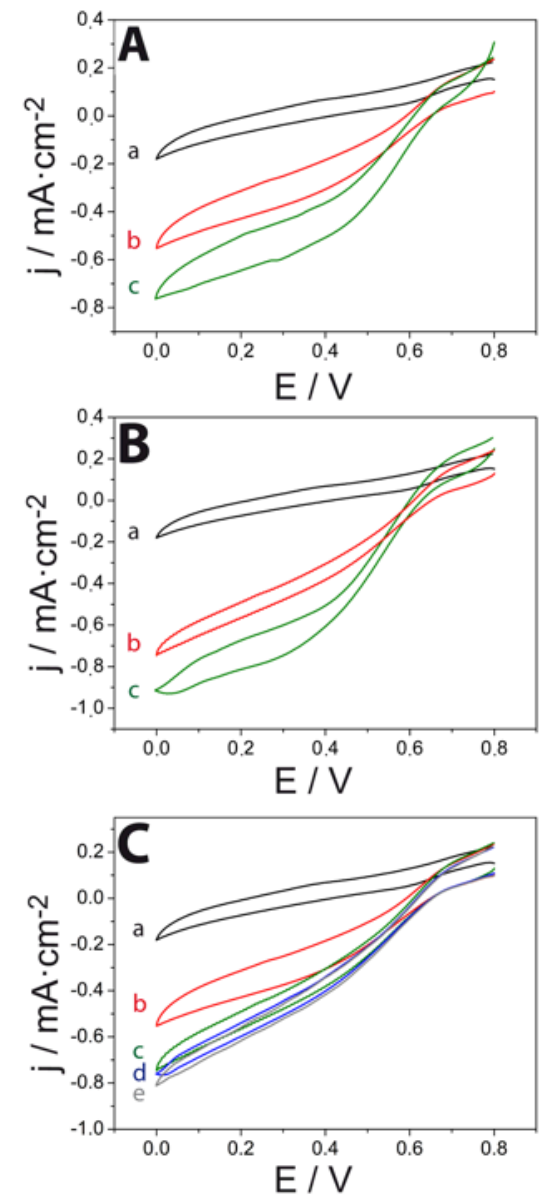

Figure 3. (A) Cyclic voltammograms recorded at $0 \mathrm{rpm}$ for a ThLc-AuNR-LDG electrode in the presence of $30 \mathrm{mM} \mathrm{NaF}$ (a), after bubbling $\mathrm{O}_{2}$ during $15 \mathrm{~min}$ in the absence of $\mathrm{NaF}(\mathrm{b}$ ), after addition of ABTS $0.1 \mathrm{mM}$ (c). (B) Cyclic voltammograms recorded at $500 \mathrm{rpm}$ for a ThLc-AuNR-LDG electrode in the presence of $30 \mathrm{mM} \mathrm{NaF}$ (a), after bubbling $\mathrm{O}_{2}$ during 15 min in the absence of $\mathrm{NaF}$ (b), after addition of ABTS $0.1 \mathrm{mM}$ (c). (C) Cyclic voltammograms of a ThLc-AuNR-LDG electrode at increasing rotation rates: (a) $0 \mathrm{rpm}$ with $\mathrm{NaF} 30 \mathrm{mM}$, (b) $0 \mathrm{rpm}$ after bubbling $\mathrm{O}_{2}$ during $15 \mathrm{~min}$ in the absence of $\mathrm{NaF}$, (c) $500 \mathrm{rpm}$, (d) 1,000 rpm, (e) 1,500 rpm. 
ThLc was firstly incubated in a solution containing $\mathrm{NaIO}_{4}$, a mild oxidizer able to convert the hydroxyl groups of the carbohydrates existing on the enzyme surface to aldehydes [36]. Afterwards the amino-functionalized AuNR-LDG electrodes were incubated in the aldehyde-modified ThLc, allowing the orientation of the enzyme with its T1 site facing the electrode surface and attaching the enzyme by establishing multiple imine bonds between the amines present at the electrode surface and the aldehydes inserted at the enzyme. This strategy is known to yield DET between the ThLc and an amino-functionalized electrode $[15,21,23]$.

Once the enzymatic electrode was assembled it was taken to an electrochemical cell to test its ability to reduce $\mathrm{O}_{2}$ by cyclic voltammetry (Figure 3). The measurement was performed at $\mathrm{pH} 4.2$ using $50 \mathrm{mM}$ acetate as buffer and $100 \mathrm{mM}$ sodium perchlorate as electrolyte. The measurement shows a reductive current as a result of a catalytic effect in presence of $\mathrm{O}_{2}$ (Figure 3A, curve b); the voltammogram reaches a quasi-plateau of reduction current density of ca. $-0.5 \mathrm{~mA} \cdot \mathrm{cm}^{-2}$. When the mediator ABTS $(0.1 \mathrm{mM})$ was added into the electrochemical cell the catalytic current density increased, showing a quasi-plateau of ca. $0.7 \mathrm{~mA} \cdot \mathrm{cm}^{-2}$ (curve c). The difference between MET and DET hints that a portion of the laccase was not immobilized successfully to perform under DET regime. When the measurements were performed under a rotation of $500 \mathrm{rpm}$ the electrode signal managed to diminish the mass-transfer limitation of $\mathrm{O}_{2}$ towards the electrode surface (Figure 3B), therefore increasing the current density measured for both DET (curve b) and DET+MET (curve c) regimes. Higher rotation rates were tested, although the voltammetric response barely increased, indicating that the $\mathrm{O}_{2}$ transport to the electrode surface was not the limiting step of the $\mathrm{O}_{2}$ bioelectrocatalytic reduction kinetics any more (not shown). In every case the reversible inhibitor $\mathrm{NaF}[37,38]$ was added to record the background signals (Figure $3 \mathrm{~A}$ and $3 \mathrm{~B}$, curve a). Figure $3 \mathrm{C}$ shows the effect of increasing the rotation rate in the absence of the mediator ABTS. As can be seen at rotation rates higher than $500 \mathrm{rpm}$, the electrocatalytic 
wave of oxygen reduction seldom changes, which suggests that DET is rate-limiting the process.

It should be noted that the LDG electrodes have a very large real surface area due to its porous structure [23], thus their modification with AuNRs should not increase significantly the electroactive area. We compare the catalytic current densities obtained for ThLc-AuNRLDG electrodes against the ones obtained for planar gold electrodes modified with the same mixture of aminoaryl diazonium derivative and $\mathrm{MH}$, and covalently bound laccase (ThLc-Au) [15], In the present work we obtain current densities ca. 12-fold higher than with the ThLc-Au disk electrodes used in [15], which Au surface area is 4-5 times lower than in ThLc-AuNRLDG electrodes. This much-higher catalytic current density obtained with the ThLc-AuNRLDG electrodes can be explained by the fact that laccase may bind also to LDG surface not covered by AuNRs.

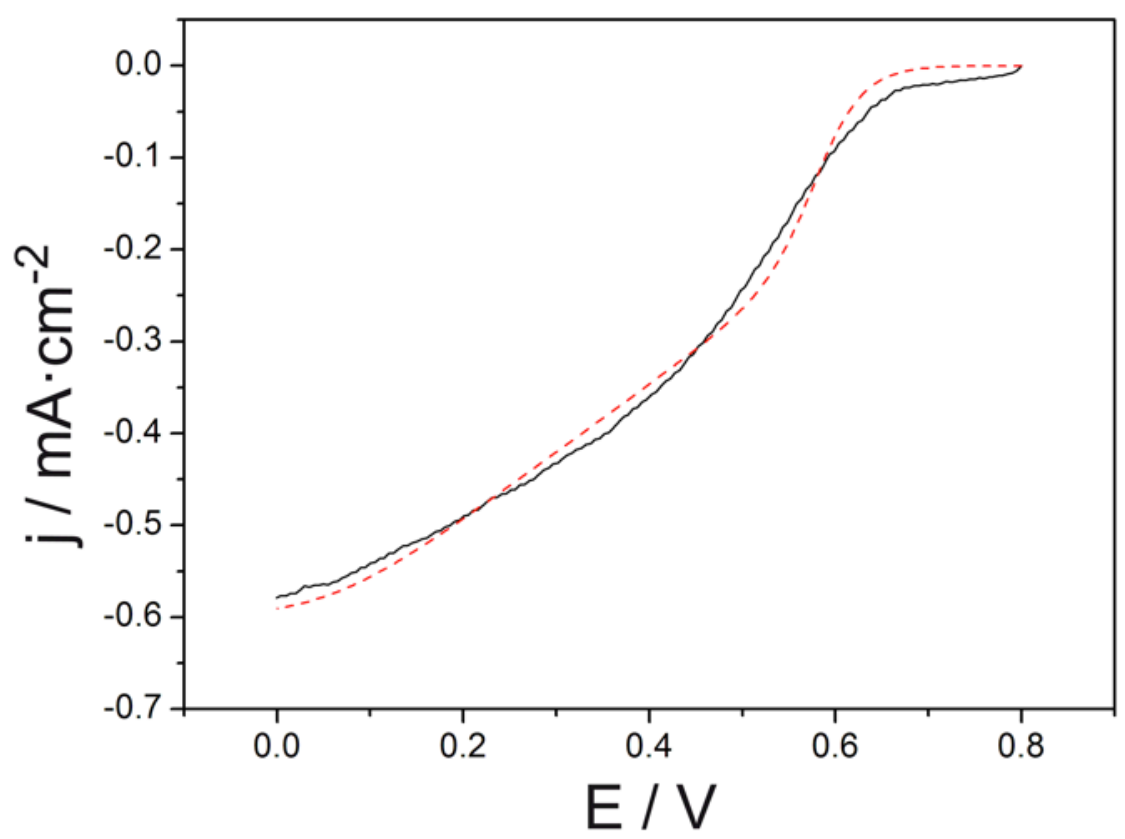


Figure 4. Blank-subtracted forward scan of the CV measured for a ThLc-AuNR-LDG electrode at $1500 \mathrm{rpm}$ and $10 \mathrm{mV} / \mathrm{s}$ after bubbling $\mathrm{O}_{2}$ during $15 \mathrm{~min}$ (black solid line) and fitted curve considering a DET rate-limited process with a distribution of non-optimally wired laccase molecules (red dashed line).

The bioelectrochemical response given by the ThLc-AuNR-LDG electrode for $\mathrm{O}_{2}$ reduction vs. redox potential was analyzed (Figure 4). To do so the forward CV scan measured under $1 \mathrm{~atm} \mathrm{O}_{2}$ was taken and the scan measured in presence of $\mathrm{NaF}$ inhibitor was subtracted. The resulting curve does not show the characteristic sigmoidal shape ending in a plateau limiting current, which is the typical response of an electrocatalytic process limited by either the enzymatic reaction kinetics or mass-transfer [39]. Instead, the electrocatalytic response resembles a process rate-limited by DET including a distribution of enzymes that are not properly connected and present different distances from their redox sites to the electrode surface, as reported by Leger et al. [31] In fact, our experimental curve for the ThLc-AuNRLDG electrode at $1500 \mathrm{rpm}$ fits in a good agreement to Leger's theoretical equation adapted to laccase electrocatalysis, giving a value of $0.79 \mathrm{~V} v s$. NHE for the potential of the redox site of the laccase involved in the DET. This potential value matches reasonably with the T1 site value determined by reported spectroelectrochemical titrations (0.78 vs NHE) $[27,40]$. The other independent parameters determined in the curve fitting were $k_{\text {cat }} / k_{0}{ }^{\text {max }}=0.003$ and $\beta d_{0}=$ 16.6. $k_{\text {cat }} / k_{0}{ }^{\max }$ corresponds to the ratio between the enzymatic reaction rate constant and the heterogeneous electron transfer rate constant at the optimal enzyme orientation, and $\beta d_{0}$ is a parameter for the orientations' dispersion of enzyme molecules taking part in the DET process [31]. In a previous work, in which we reported that AuNPs acted as electronic bridges between ThLc and LDG, approximately half of the immobilized laccase molecules were optimally wired to the electrode following a Nernstian-controlled electron transfer process, 
whereas the other half followed the non-optimal DET rates distribution [23]. The Nernstiancontrolled process has not been observed in the case of the AuNRs-modified electrode, where almost all the enzymes follow the Leger's kinetic regime. A possible explanation for this kinetic behaviour that differs from the AuNP electrodes can be attributed to the larger size of the AuNRs. In fact, more efficient DET was measured for 5 nm-diameter AuNPs than for 16 nm-sized ones [23]. Furthermore, there are very recent reports where is shown that nanoparticles ranging $20-80 \mathrm{~nm}$ in diameter do not alter the DET nor the bioelectrocatalytic rates of the immobilized enzyme molecules [40]. Therefore, these results support that when the Au nanoelements are larger than the immobilized laccases the improvement effect in the electronic coupling does not take place. The lower efficiency of the AuNRs than the AuNPs in wiring the DET of the laccases could be related to the higher potentials required to reduce the Au oxides formed on the AuNR-LDG electrode being due to a higher kinetic barrier for electron transfer [41]. Besides, the higher value of $\beta d_{0}$ (16.6) obtained in the fitting for the ThLc-AuNR-LDG electrode compared to the AuNPs-based electrode one (11.0) [23] suggests a higher dispersion of laccase molecules orientations on the AuNRs due to the presence of different crystalline gold facets.

The ThLc-AuNR-LDG electrodes were stable during a measuring day and could be stored at $4{ }^{\circ} \mathrm{C}$ during few days while keeping their stability. The study of long-term stability was out of the scope of this work, however in previous work on ThLc-AuNP-LDG we reported that $40 \%$ of the catalytic current was maintained after 4 days of continuous operation by chronoamperometry [23]. Taking into account that the Au nanoelements and the enzyme were immobilized in the same way in both works, we should expect similar operational stability for the ThLc-AuNR-LDG.

\section{Conclusions}


AuNRs with an average size of $31 \pm 6 \mathrm{~nm}$ have been prepared and covalently attached to LDG electrodes as nanostructured platform for laccase immobilization. High electrocatalytic currents of oxygen reduction up to $-0.6 \mathrm{~mA} / \mathrm{cm}^{2}$ are measured by DET of the immobilized laccase. Addition of the redox mediator ABTS increased by $28 \%$ the current density, suggesting that most of the immobilized laccase molecules have an adequate orientation for DET process. Fitting of the experimental curve of the electrocatalytic current dependence on the applied potential to the theoretical one indicates that the process at high rotation of ThLc-AuNR-LDG electrodes is rate-limited by DET from the $\mathrm{Cu} \mathrm{T} 1$ atom of laccase to the electrode surface. Moreover, the electrochemical response based on DET reflects a wider distribution of non-optimally wired laccase molecules that has been previously observed for AuNPs of smaller sizes. Thus, the results obtained with AuNRsmodified electrodes could be due to the larger size of the AuNRs than the laccase molecules and to their different crystal facets.

\section{Acknowledgements}

This work was funded by the VII Framework Program (BIOENERGY FP7-PEOPLE2013-607793 project).

\section{References}

[1] E.I. Solomon, A.J. Augustine, J. Yoon, $\mathrm{O}_{2}$ Reduction to $\mathrm{H}_{2} \mathrm{O}$ by the Multicopper Oxidases. Dalton Trans. 139 (2008) 3921-3932.

[2] E. Solomon, U. Sundaram, T. Machonkin, Multicopper Oxidases and Oxygenases. Chem. Rev. 96 (1996) 2563-2606.

[3] S. Shleev, V. Andoralov, M. Falk, C.T. Reimann, T. Ruzgas, M. Srnec, U. Ryde, L. Rulisek, On the Possibility of Uphill Intramolecular Electron Transfer in Multicopper 
Oxidases: Electrochemical and Quantum Chemical Study of Bilirubin Oxidase. Electroanalysis 24 (2012) 1524-1540.

[4] L. dos Santos, V. Climent, C.F. Blanford, F.A. Armstrong, Mechanistic Studies of the 'Blue' $\mathrm{Cu}$ Enzyme, Bilirubin Oxidase, as a Highly Efficient Electrocatalyst for the Oxygen Reduction Reaction. PhysChemChemPhys 12 (2010) 13962-13974.

[5] S.-K. Lee, S. G. DeBeer, W. E. Antholine, B. Hedman, K. O. Hodgson, E. I. Solomon, Nature of the Intermediate Formed in the Reduction of $\mathrm{O}_{2}$ to $\mathrm{H}_{2} \mathrm{O}$ at the Trinuclear Copper Cluster Active Site in Native Laccase. J. Am. Chem. Soc. 124 (2002) 6180-6193.

[6] S. Shleev, J. Tkac, A. Christenson, T. Ruzgas, A.I. Yaropolov, J.W. Whittaker, L. Gorton, Direct Electron Transfer between Copper-Containing Proteins and Electrodes. Biosens. Bioelectron. 20 (2005) 2517-2554.

[7] S.C. Barton, J. Gallaway, P. Atanassov, Enzymatic Biofuel Cells for Implantable and Microscale Devices. Chem. Rev. 104 (2004) 4867-4886.

[8] M. Falk, M. Alcalde, P.N. Bartlett, A. L. De Lacey, L. Gorton, C. Gutierrez-Sanchez, R. Haddad, J. Kilburn, D. Leech, R. Ludwig, et al. Self-Powered Wireless Carbohydrate/Oxygen Sensitive Biodevice Based on Radio Signal Transmission. Plos One 9 (2014) e109104.

[9] K. MacVittie, J. Halamek, L. Halamkova, M. Southcott, W.D. Jemison, R. Lobeld, E. Katz, From "Cyborg" Lobsters to a Pacemaker Powered by Implantable Biofuel Cells. Energy Environ. Sci. 6 (2013) 81-86.

[10] M. Falk, V. Andoralov, Z. Blum, J. Sotres, D.B. Suyatin, T. Ruzgas, T. Arnebrant, S. Shleev, Biofuel Cell as a Power Source for Electronic Contact Lenses. Biosens. Bioelectron. $2012,37,38-45$.

[11] S.C. Barton, H.H. Kim, G. Binyamin, Y. Zhang, A. Heller, The "Wired" Laccase Cathode: High Current Density Electroreduction of $\mathrm{O}_{2}$ to Water at $+0.7 \mathrm{~V}[\mathrm{NHE}]$ at $\mathrm{pH}$ 5. J. Am. Chem. Soc. 123 (2001) 5802-5803. 
[12] Y. Ackermann, D.A. Guschin, K. Eckhard, S. Shleev, W. Schuhmann, Design of a Bioelectrocatalytic Electrode Interface for Oxygen Reduction in Biofuel Cells Based on a Specifically Adapted Os-Complex Containing Redox Polymer with Entrapped Trametes hirsuta Laccase. Electrochem. Commun. 12 (2010) 640-643.

[13] C.F. Blanford, C.E. Foster, R. S. Heath, F.A. Armstrong, Efficient Electrocatalytic Oxygen Reduction by the 'Blue' Copper Oxidase Laccase Directly Attached to Chemically Modified Carbons. Faraday Discuss. 140 (2009) 319-335.

[14] M.S. Thorum, C.A. Anderson, J.J. Hatch, A.S. Campbell, M.N. Marshall, S.C. Zimmerman, Y. Lu, A.A. Gewirth, Direct, Electrocatalytic Oxygen Reduction by Laccase on Anthracene-2-methanethiol-Modified Gold. J. Phys. Chem. Lett. 1 (2010) 2251-2254.

[15] M. Pita, C. Gutierrez-Sanchez, D. Olea, M. Velez, C. Garcia-Diego, S. Shleev, V.M. Fernandez, A.L. De Lacey, High Redox Potential Cathode Based on Laccase Covalently Attached to Gold Electrode. J. Phys. Chem. C 115 (2011) 13420-13428.

[16] C.Vaz-Domínguez, M. Pita, A.L. De Lacey, S. Shleev, A. Cuesta, Combined ATRSEIRAS and EC-STM Study of the Immobilization of Laccase on Chemically Modified Au Electrodes. J. Phys. Chem. C 116 (2012) 16532-16540.

[17] M. Dagys, K. Haberska, S. Shleev, T. Arnebrant, J. Kulys, T. Ruzgas, Laccase-Gold Nanoparticle Assisted Bioelectrocatalytic Reduction of Oxygen. Electrochem. Commun. 12 (2010) 933-935.

[18] T. Miyake, S. Yoshino, T. Yamada, K. Hata, M. Nishizawa, Self-Regulating EnzymeNanotube Ensemble Films and Their Application as Flexible Electrodes for Biofuel Cells. J. Am. Chem. Soc. 133 (2011) 5129-5134.

[19] M. T. Meredith, M. Minson, D. Hickey, K. Artyushkova, D.T. Glatzhofer, S.D. Minteer, Anthracene-Modified Multi-Walled Carbon Nanotubes as Direct Electron Transfer Scaffolds for Enzymatic Oxygen Reduction. ACS Catal. 1 (2011) 1683-1690. 
[20] H.R. Luckarift, D.M. Ivnitski, C. Lau, C. Khripin, P. Atanassov, G.R. Johnson, GoldDecorated Carbon Composite Electrodes for Enzymatic Oxygen Reduction. Electroanalysis 24 (2012) 931-937.

[21] (a) C. Gutiérrez-Sánchez, W. Jia, Y. Beyl, M. Pita, W. Schuhmann, A.L. De Lacey, L. Stoica, Enhanced Direct Electron Transfer between Laccase and Hierarchical Carbon Microfibers/Carbon Nanotubes Composite Electrodes. Comparison of Three Enzyme Immobilization Methods. Electrochim. Acta 82 (2012) 218-223.

[22] M. Sosna, L. Stoica, E. Wright, J. Kilburn, W. Schuhmann, P. N. Bartlett, Mass transport controlled oxygen reduction at anthraquinone modified 3D-CNT electrodes with immobilized Trametes hirsuta laccase. Phys.Chem.Chem.Phys 14 (2012) 11882-11885.

[23] C. Gutiérrez-Sánchez, M. Pita, C. Vaz-Domínguez, S. Shleev, A.L. De Lacey, Gold Nanoparticles as Electronic Bridges for Laccase-Based Biocathodes. J. Am. Chem. Soc. 134 (2012) 17212-17220.

[24] U. Oesch, J. Janata, Electrochemical Study of Gold Electrodes with Anodic Oxide Films. 1. Formation and Reduction Behaviour of Anodic Oxides on Gold. Electrochim. Acta 28 (1983) 1237-1246.

[25] C. Vaz-Dominguez, S. Campuzano, O. Rüdiger, M. Pita, M. Gorbacheva, S. Shleev, V.M. Fernandez, A.L. De Lacey,. Laccase Electrode for Direct Electrocatalytic Reduction of $\mathrm{O}_{2}$ to $\mathrm{H}_{2} \mathrm{O}$ with High Operational Stability and Resistance to Chloride Inhibition. Biosens. Bioelectron. 24 (2008) 531-537.

[26] C. Gutiérrez-Sánchez, M. Pita, M.D. Toscano, A. L. De Lacey, Bilirubin Oxidase-Based Nanobiocathode Working in Serum-Mimic Buffer for Implantable Biofuel Cell. Electroanalysis 25 (2013) 1359-1362.

[27] S. Shleev, O.V. Morozova, O.V. Nikitina, E.S. Gorshina, T.V. Rusinova, V.A. Serezhenkov, D.S. Burbaev, I.G. Gazaryan, A.I. Yaropolov, Comparison of Physico- 
Chemical Characteristics of Four Laccases from Different Basidiomycetes. Biochimie 86 (2004) 693-703.

[28] M.M. Bradford, A Rapid and Sensitive Method for the Quantitation of Microgram Quantities of Protein Utilizing the Principle of Protein-Dye Binding. Anal. Biochem. 72 (1976) 248-254.

[29] M.R.K. Ali, B. Snyder, M.A. El-Sayed, Synthesis and Optical Properties of Small Au Nanorods Using a Seedless Growth Technique. Langmuir 28 (2012) 9807-9815.

[30] D. Duff, A. Baiker, P.P. Edwards, A New Hydrosol of Gold Clusters. 1. Formation and Particle Size Variation. Langmuir 9 (1993) 2301-2309.

[31] C. Leger, A.K. Jones, S.P.J. Albracht, F.A. Armstrong, Effect of a Dispersion of Interfacial Electron Transfer Rates on Steady State Catalytic Electron Transport in [NiFe]Hydrogenase and Other Enzymes. J. Phys. Chem. B 106 (2002) 13058-13063.

[32] K. Murata, K. Kajiya, N. Nakamura, H. Ohno, Direct Electrochemistry of Bilirubin Oxidase on Three-Dimensional Gold Nanoparticle Electrodes and its Application in a Biofuel Cell. Energy Environ. Sci. 2 (2009) 1280-1285.

[33] M. Grzelczak, J, Perez-Juste, F.J. Garcia de Abajo, L.M. Liz-Marzan, Optical Properties of Platinum-Coated Gold Nanorods, J. Phys. Chem. C 111 (2007), 6183-6188.

[34] F. Mirkhalaf, D.J. Schiffrin, Electrocatalytic Oxygen Reduction on Functionalized Gold Nanoparticles Incorporated in a Hydrophobic Environment. Langmuir 26 (2010) $14995-15001$

[35] A. Benedetto, M. Balog, P. Viel, F. Le Derf, M. Salle, S. Palacin, S. Electro-reduction of Diazonium Salts on Gold: Why Do We Observe Multi Peaks? Electrochim. Acta 53 (2008) $7117-7122$.

[36] G. Gupta, V. Rajendran, P. Atanassov, Bioelectrocatalysis of Oxygen Reduction Reaction by Laccase on Gold Electrodes. Electroanalysis 16 (2004) 1182-1185. 
[37] A. Naki, S.D. Varfolomeev, Mechanism of the Inhibition of Laccase Activity from Polyporus versicolor by Halide-Ions. Biochemistry-Moscow 46 (1981) 1344-1350.

[38] F. Xu, R.M. Berka, J.A. Wahleithner, M.A. Nelson, J.R. Shuster, S.H. Brown, A.E. Palmer, E.I. Solomon, Site-Directed Mutations in Fungal Laccase: Effect on Redox Potential, Activity and pH Profile. Biochem. J. 334 (1998) 63-70.

[39] C. Leger, P. Bertrand, Direct Electrochemistry of Redox Enzymes as a Tool for Mechanistic Studies. Chem. Rev. 108 (2008) 2379-2438.

[40] D. Pankratov, R. Sundberg, D.B. Suyatin, J. Sotres, A. Barrantes, T. Ruzgas, I. Maximov, L. Montelius, S. Shleev, The Influence of Nanoparticles on Enzymatic Bioelectrocatalysis. RSC Adv. 4 (2014) 38164-38168.

[41] J. S. Jirkovsky, M. Halasa, D. J. Schiffrin, Kinetics of Electrocatalytic Reduction of Oxygen and Hydrogen Peroxide on Dispersed Gold Nanoparticles. PhysChemChemPhys 12 (2010) 8042-8052.

\section{TOC}
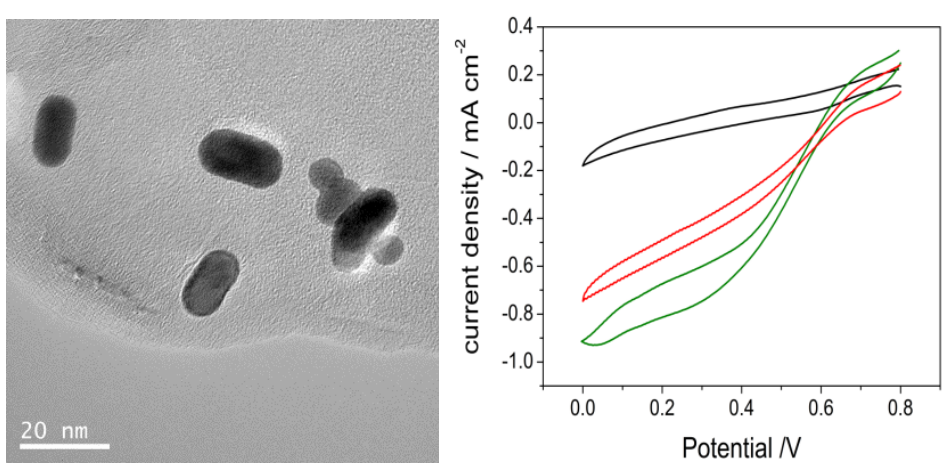